\title{
Situational Leadership And Diversity Management Coaching Skills
}

Bahaudin G. Mujtaba, Nova Southeastern University, USA

Jatuporn Sungkhawan, Southeast Bangkok College, Bangkok, Thailand

\begin{abstract}
Leadership and diversity management have been part of the work life since the beginning of formal organizations and a critical element of globalization. The authors provide an overview of situational leadership and link it to diversity management so the focus can remain on productivity rather than personalities and biases which are part of each society and individual. Based on personal training experiences of the authors, this conceptual and practical paper provides a model to link situational leadership to diversity in the workplace through effective coaching skills.
\end{abstract}

Keywords: leadership, diversity, diversity management, coaching skills, situational leadership, communication, and management.

\section{INTRODUCTION}

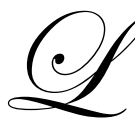

eaders and managers are part of the society and deal with diversity challenges and opportunities every single day. Those managers and leaders who are properly prepared to deal with the challenges and take advantages of the opportunities it offers will likely succeed by being effective coaches in a diverse workplace. Discriminatory practices are widespread in the society and, at times, it surfaces in the workplace which can cause major challenges for managers and leaders. Unfair aspects of discrimination often take root from societal biases, stereotypes, and misinformation. Instead of passing on societal biases and treating employees unfairly based on stereotypes and misinformation, managers can use situational leadership practices by concentrating on the performance of each associate and developing them progressively based on their level of readiness to take on new responsibilities and initiatives.

\section{DIVERSITY CHALLENGES FOR ORGANIZATIONS AND MANAGERS ${ }^{1}$}

Diversity is a subject that can be very powerful and emotional for everyone who deals with it either directly or indirectly. Diversity topics deal with issues of being different and alike, inspiration and perspiration, sadness and gladness, privilege and lack thereof, culture and religion, tolerance and justice, and hatred and animosity. Diversity challenges and opportunities impact all nations around the world to one extent or another. Today issues of cultural identification, religious protection, ethnic cleansing, racial supremacy, oppression of minority groups, unfair compensation to various groups of people based on their minority status or gender, and other such critical issues impact various nations around the world. For example, even countries such as the United States of America and Russia are suffering from racial conflicts caused by groups of individuals claiming "white supremacy" and privilege.

There are hundreds of hate groups in the United States (as well as around the world), such as the Klu Klux Klan (KKK) and other extremists, that are active in promoting hatred and animosity toward minorities or those who are "different." As a matter of fact, there are at least 500 "hate group" websites on the internet spreading the message of hate and racism. As reported by the Good Morning America Show of ABC (June 11, 2006), the internet seems to be a growing tool for hate groups to spread their message and attract new members. ABC showed videos of KKK members demonstrating on June 10, 2006, yelling and screaming that they want Mexicans, Jews, and illegal immigrants out of the United States. The "Intelligence Report" from spring 2006, which is published by the

\footnotetext{
${ }^{1}$ See Mujtaba, B. G. (2007). Workplace Diversity Management: Challenges, Competencies and Strategies.
} 
Southern Poverty Law Center, states that "hate groups are up 33\% over the last five years." The report goes on to say that "For almost 30 years, the National Socialist Movement was a forgotten bit player on the neo-Nazi scene, overshadowed by groups like the National Alliance and Aryan Nations. But as other groups collapsed, NSM has exploded, launching a new white power music label and adding a plethora of new chapters." The report talks about "Books on the Right," stating that "After a sympathetic portrayal of a key neo-Nazi leader, a tenured professor at the University of Vermont's latest books celebrates white nationalism." The section about "Updates on Extremism and the Law" report that a white supremacist, who is also known for yelling racial epithets, was arrested on October 2005 for imprisoning, torturing and sexually assaulting two black women. This person, according to police officers, kept the women locked up in a shipping container in his backyard near Philadelphia (Intelligence Report, 2006). Such forms of blatant discrimination and illegal behaviors still seem to be commonplace today by some groups of individuals with extreme views in certain nations around the world. For example, there were many minority individuals killed during 2006 in the former Soviet Union by groups of white individuals who felt threatened by the diversity in their country. One racist Russian, interviewed on May 2006 by the Public Broadcasting System (PBS), said that he is the leader of one group and will continue severe hate crimes because he feels as though all the opportunities for him and "his people" have transitioned to minorities since they now own most businesses in "his" country. Similarly, Germany has seen a rise in their cases of racism and hatred of non-Whites in the last two years. In 2006, several non-White individuals were targets of racism, vandalism and beatings by some Germans that belong to various groups that encourage racial divisions. Racial and religious divisions among various groups of people in Iraq have been on the rise during the occupation of that country by the American and British soldiers. To increase cultural sensitivity among the foreign military forces in Iraq, all American soldiers were required to complete a cultural sensitivity training to increase their awareness of diverse cultures and the people of Iraq. After a thorough investigation of American soldiers allegedly killing 24 innocent men, women and children in one Iraqi village, the 130,000 soldiers stationed there, as of July 2006 , were required to also complete a standardized training in the areas of legality, ethics and morality so they can be better prepared to treat people with respect and dignity in all circumstance. With the election of President Barak Obama in the United States, the White supremacy groups have further increased their activities, propaganda, and recruitment efforts in 2009.

As can be seen from these brief statements thus far, diversity is a major local, national and international challenge and an opportunity for every human being if we are to live in a peaceful and healthy world. Of course, differences and its perceptions are not always so extreme that they lead to innocent individuals being abused, injured or killed. For example, differences can exist in the compensation of individuals in different ranks, or as per their gender. Males tend to earn more annual income than many female employees who are performing the same jobs in various industries. Upper management usually tends to earn more money than lower level employees. According to a study by the Federal Reserve in 2005-2006, chief executive officers' salaries in the United States are now about 170 times greater than the average worker's pay, up from about 40 times greater recorded in the 1970s. In the United Kingdom, for the chief executive officers' salaries, the multiple is 22, and in Japan it is about 11 when compared with non-management workers. Such differences in compensation can also be issues of diversity, equality, fairness, and the effective management of a firm's human resources. Overall, understanding diversity is about feeling comfortable and maximizing productivity in an interdependent or in an interrelated society where each workplace is a microcosm of the world's demographics.

The subject of diversity requires examining one's own beliefs and values as well as learning the skills of dealing appropriately with those whose beliefs and values may be very different. Diversity, like communication, is a fact of life. It is natural, irreversible; and its tolerance is a necessity of life if one is to function effectively in this universe. Diversity has made our lives more interesting, attractive and less monotonous. Simultaneously, it has made our lives more complicated, challenging and unpredictable. It is not uncommon to become offended by people's actions, sayings, thoughts, and overall behaviors in diverse teams and general group settings in today's workforce. Some of these comments, thoughts and actions may make us uncomfortable because they challenge our deeply-held beliefs and values that have been embedded into our subconscious minds for years and decades since childhood.

Because of many diversity dimensions, our unique backgrounds, religious beliefs, societal norms, and cultural differences, we may view the same situation in two different ways. For example, many people see a hard working manager who is always working late, meeting deadlines, and constantly "pushing" his/her people to do more each and every day as proactive, assertive and energetic individuals. On the other hand, the same manager 
could be seen as egotistical, self-centered, pushy, materialistic, and rude by others from different cultures or backgrounds. It is not that one view is right and the other is wrong; they are just different and appropriate under certain circumstances and conditions. The key is to understand what constitutes "normal," "acceptable," and "correct" behavior in each situation and environment. These different perspectives have existed in our societies for thousands of years in different regions. Since technology has made it easier to travel around the world in a matter of hours, the world has shrunk and has become smaller. This means that many different groups of individuals could be living in similar geographical locations.

Cultural, generational, financial, personal, and professional diversity have been part of humanity since the days of Adam and Eve. Diversity impacts every aspect of a person's life. Today's population is more diverse than ever before and the workforce population has been changing rapidly along with it. Such diverse workers and managers should be culturally competent and be able to effectively manage diversity if they are to work synergistically in today's competitive work environment. Becoming an effective diversity advocate or "manager" and learning to remain as such is a moral imperative for all leaders in today's global world. Being an effective leader or manager in a diverse environment requires expecting the same standards from all workers regardless of their race, gender, language, sexual orientation, age, and general background. Managers should not evaluate or rate workers differently because of their gender, nationality, or language, since such differences can have negative consequences as a result of the self-fulfilling prophecy. All workers must earn their evaluations based on actual performance and according to the formal evaluation criteria communicated. Managers and team leaders are obligated to treat each person fairly and expect high standards from them regardless of their gender, ethnicity/nationality, primary language, age, experience, disability, and other non-job related variables. Organizations should also provide reasonable accommodations, privileges, opportunities, incentives, and facilities to attract and retain diverse employees and customers.

As leaders, professionals, executives, and senior managers, we can do a lot of things to enhance the productivity of our people by being a role model, providing diversity training and development workshops, and by making sure people treat each other fairly. Regardless of your rank, position title or power, chances are high that you cannot erase years and centuries of cultural bias and personal opinions that exist in the society. However, what you can do is to consistently insist that your workplace is free of bigotry and full of opportunity for all individuals. Therefore, you must first understand and support cultural competency and diversity management concepts. Cultural competency is the continuous learning process that enables one to function effectively in the context of cultural differences. Diversity management is the process of becoming culturally competent by understanding the needs, wants, desires, strengths, weaknesses, beliefs, and values of each person, while providing him or her the opportunity to contribute to the collective genius of the whole. Diversity management is about creating synergistic results that are equal to or greater than the sum of the individual parts. Managing diversity is about enabling each member of the workforce to perform above and beyond his or her potential. Managing diversity is about making sure people are not led to believe a lie or stereotypes so they can be free of guilt and "live happily ever after."

\section{LEADERSHIP OPPORTUNITIES FOR ORGANIZATIONAL MANAGERS}

Situational Leadership theories, often categorized as contingency theories in academia, teach that there is no one best way of leadership since effectiveness depends on the situation. Effective leaders adapt their styles to fit a broad range of individuals and variables impacting their situations. Dr. Paul Hersey claims that "leadership is any attempt to influence the behavior of another person or persons," and effective leadership is adapting one's behavior to the performance needs of the person or persons (Personal Communication, February 2008 in Escondido, CA). Effective leaders diagnose, adapt, and communicate based on the readiness of their followers in the workforce and other situational variables. Dr. Hersey defined a person's readiness level as their ability and willingness to perform the task at hand and this definition considers two types of readiness: job and psychological. Knowing a person's (follower's) readiness level and effectively adapting one's leadership style to match the readiness level is an important element of making sure the job gets done successfully. As such, Situational Leadership applies to professionals in business, government, the community, volunteers, religious leaders, as well as to parents, and others who have a need to influence the effort of others. 
Figure 1 - Situational Leadership Model (Mujtaba, 2007)

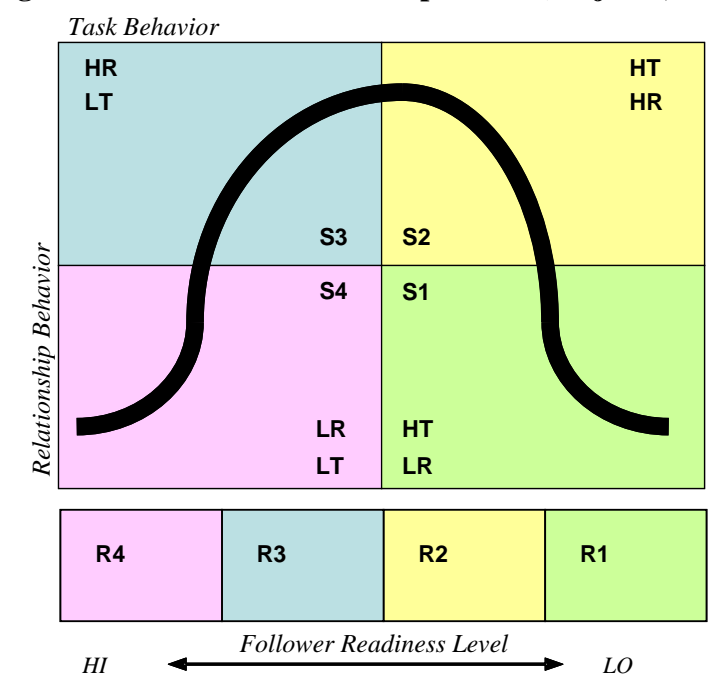

Situational Leadership Theory, according to Hersey, Blanchard and Johnson (2001), proposes that individuals can change their leadership style (behavior) depending on the situation and the readiness of the follower. Drs. Hersey and Blanchard are of the mindset that leaders can and do change their styles depending on with whom they are working. Dr. Hersey stated that Situational Leadership is the most popular leadership model of the day because it is practical and applies to every aspect of life, including government and corporate management. This style of leadership has been around and advocated by others in the past. For example Machiavelli wrote a little book titled "The Prince," and Dr. Hersey said if one replaces the word 'Prince' with leader in Machiavelli's book, then essentially one is practicing a certain aspect of Situational Leadership. Dr. Hersey sees situational leadership as more of a model, rather than a theory, because a model is something that can be replicated and applied in various settings and cultural environments. He said that the situational leadership model can help people learn to change their behaviors so they can become more effective leaders. Dr. Hersey believes that leaders can learn to positively impact different kinds of situations that face them at any moment. Publix Super Market used the three day situational leadership seminars with over one thousand managers to prepare them for effective leadership with their employees. Managers liked the model because it is friendly and easy to understand. This is why many corporate personnel throughout the world have received training in situational leadership. In this model, the "situation" is defined by the "readiness" of the followers to successfully complete the job. A person who is high on job readiness and willingness is likely to have the necessary knowledge, abilities and motivation to perform the job without much direction from the leader. Figure 1 provides a visual representation of the four quadrants along with the four leadership styles.

Figure 1 shows how the "Readiness" scale goes from high to low readiness levels and it is displayed under the leadership matrix to match the four leadership styles. The four quadrants are as follows:

1. S1- high task (HT), low relationship (LR)

2. S2- high task(HT), high relationship (HR)

3. S3- high relationship (HR), low task (LT)

4. S4- low relationship (LR), low task (LT)

According to this model, an effective leader (person exerting influence) often has a dominant style but can move from one style to another depending on the situation. The Situational Leadership model is based on the interactive interplay among direction (task behavior) provided by the leader, socio-emotional support (relationship behavior) provided by the leader and the readiness of the follower on the specific task that needs performing. According to the model, there are four readiness levels: 
1. R1- followers are unable and unwilling to perform the task.

2. $\quad$ R2- followers are unable but willing to perform the task.

3. R3- followers are able but unwilling to perform the task.

4. R4- followers are able and willing to perform the task.

Situational Leadership model attempts to keep a balance between high tech (task behaviors) and high touch (relationship behavior). Once the followers' readiness is determined, a manager or a leader can choose from the four leadership styles suggested by Hersey and Blanchard's model that focus to some extent either on task behavior or relationship behavior. Task behavior is the extent to which leaders engage in top-down communication by explaining what the follower is to do, as well as when, where, and how each function is to be accomplished. Relationship behavior is the extent to which leaders engage in joint communication with followers while providing socio-emotional support. The four corresponding leadership styles that match these readiness $(\mathrm{R})$ levels are as follows:

1. RI- matches best with "Telling," high task-low relationship. The manager or the leader defines the roles needed to the do the job and tells followers what, where, how, and when to do the tasks.

2. R2- matches best with "Selling," high task-high relationship. The manager or leader provides step-by-step and disciplined guidelines to get the job done while being supportive.

3. R3- matches best with "Participating," low task-high relationship. The managers, or the leader, along with followers (employees and/or colleagues) jointly decide how to get the job done with the required quality standards.

4. $\quad$ R4- matches best with "Delegating," low task-low relationship. The manager or leader provides little directions and little support to the followers since they know how to get the job done and they are very willing to do it independently.

Of course, there are perhaps thousands of situations that could use many different leadership styles. The situational leadership model has four leadership styles to keep it simple and easy to understand, so it can be applied by individuals of different skill levels and competencies. In each situation, the model encourages managers to match the style with the followers' level of readiness thus providing the most appropriate amount of task behavior and relationship behavior for the specific task on hand. Dr. Paul Hersey (Personal Communication with Dr. Paul Hersey in Escondido, CA, February 2008) provides the following recommendations for each of the four leadership styles:

- $\quad$ Style one or telling is best when attempting to influence low levels of readiness. Alternative words that describe the telling style are guiding, directing, and establishing.

- $\quad$ Style two or selling is best when attempting to influence low to moderate levels of readiness. The leader attempts to get the follower to buy into doing the task psychologically. Alternative words that describe the selling style are explaining, clarifying and persuading.

- $\quad$ Style three or participating is best when attempting to influence moderate to high levels of readiness. The key is to encourage the follower to participate and get involved. Alternative words that describe the participating style are encouraging, collaborating and committing.

- Style four or delegating is best when attempting to influence high levels of readiness. This is where the follower has almost all of the decisions for both decision-making and implementation of the activities to get the job done. Alternative words that describe the delegating style are observing, monitoring and fulfilling.

As the readiness of the follower (person performing the specific task) increases in terms of performance, the leader should adapt by reducing task behavior and increasing relationship behaviors. As the follower becomes totally ready by showing successful performance, the leader should reduce both task and relationship behaviors to the lowest level possible. Overall, managers apply this model similar to medical practitioners who deal with patients that complain about a pain in different parts of their bodies. The medical doctor must first diagnose the cause of the problem and then prescribe the right medication to alleviate the problem or pain. Dr. Hersey says that a prescription without diagnosis can basically amount to malpractice. Similarly, a manager or a leader must first diagnose the follower's level of readiness with each person in his/her team, which can include many personalities, and then act with an appropriate leadership style. Diagnosis, or assessing ability and willingness of the follower to see what leadership style is needed, should be followed by matching an appropriate leadership behavior and then 
implementation of the leadership style to make sure the job gets done with the required quality in the allotted timeframe.

Dr. Hersey and his co-facilitators during their one-week workshop on Situational Leadership introduced five different personalities which exist in each work environment, which are 1) the superstars that do their jobs well, 2) those who tend to consistently ask questions in order to confirm their understanding of new material, 3) workers who are fully motivated but not able to perform the task, 4) individuals who are not sure why they are doing certain tasks, and 5) personalities with negative attitude that think and say "everything sucks." Some of these personalities in the workplace may have the attitude that "the only leaders in this department are you and I, but I am not sure about you." A leader is likely to face each of these personalities as new jobs, tasks, technologies, and duties are being introduced. As a matter of fact, at times, a person may fall into each of these personalities depending on his/her level of readiness, how well s/he is being taught the skills or lack thereof, morale of the follower and his/her colleagues, and the fairness of the compensation or rewards for the completion of the tasks. Because there are so many variables impacting one's personality and attitude toward tasks, the leader should diagnose the follower's level or readiness (personality) and then take appropriate steps and use a relevant style. Dr. Hersey, during a question and answer session on February $28^{\text {th }} 2008$, mentioned that diagnosing can serve many functions such as the assessment of individuals in each group or class of learners and a leader must stay close to these individuals in order to maintain productivity. Diagnosing must be done carefully to make sure the follower is honest in expressing ability and attitude (willingness) so one can deduce the right conclusions. When monitoring one's own pulse (or another person's pulse) using the left wrist area, pushing too hard on the hand can block the circulation of blood and eliminate the pulse which can lead to the wrong conclusion. So, in this case one must reduce the force to an appropriate level and allow for the natural flow of blood in order to be able to count the pulse. So, external variables controlling behavior should also be taken into consideration when diagnosing one's level of readiness. Nonetheless, the situational leadership concept requires diagnoses before prescription in order to make sure the leader uses the right leadership style with the follower.

The concept of Situational Leadership applies equally well with/and by both men and women, and can apply with the same level of effectiveness across different cultures with different people groups. When applied effectively, managers are likely to stay focused on the performance of their employees and, regardless of their personal biases or stereotypes about the workers, they will progressively help associates to move into higher levels of readiness for each task.

\section{SITUATIONAL COACHING AND SUPPORTING EMPLOYEES}

Since many organizations try to enhance their productivity and competitiveness against a major rival, one trend is trying to nurture a learning culture into their organization. In order to achieve this endeavor, the manager's role need to be shifted to a developmental manager or leader as a coach that focuses more in supporting employees to learn and to improve their competencies (hands) and motivation (heart). To be more effective in leading diverse people, situational leadership foundation applies in this trend with some integration with the coaching model as well as effective communication and learning styles. Managers should not only be aware of their leading styles and adapt appropriately to the employee's readiness but also need to be aware of their own personality characteristics regarding communication with others, which will heavily influence and determine their style of coaching or leading. There are four communication styles for coaches: Senser (controller), Intuitor (persuader), Feeler (supporter), and thinker (analyzer).

- Senser: The senser communication style tends to lead people according to situational leadership (telling/selling/participating/empowering) by focusing on action, getting right to the point, and not wanting to wait.

- Intuitor: The intuitor communication style tends to lead people according to situational leadership (telling/selling/participating/empowering) by sharing ideas, concepts or theories, seeing all possibilities, motivating, inspiring, and focusing on associate's future.

- $\quad$ Feeler: The feeler communication style tends to lead people according to situational leadership (telling/selling/participating/empowering) by caring for others, providing support, and talking about the past. 
- $\quad$ Thinker: The thinker communication style tends to lead people according to situational leadership (telling/selling/participating/empowering) by staying focused on facts, information, rules, and established procedures.

A coach has to understand emotional intelligence and work to increase the ability of leading people through self-awareness by observing one's communication style when leading.

Figure 2 - Situational Coaching Model

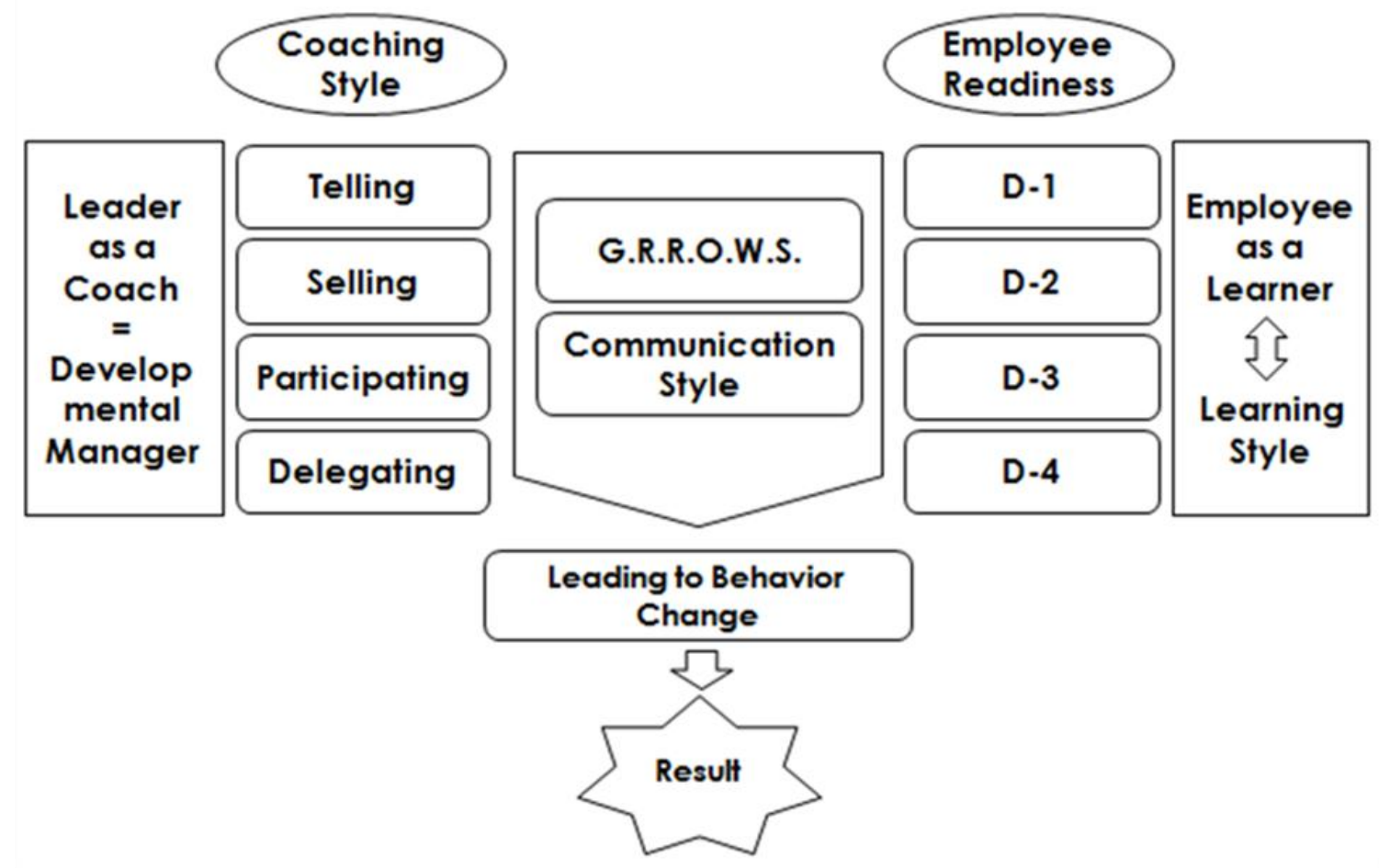

Figure 2 shows the relationship among coaching style, coaching process, communication style, and learning styles in the situational leadership model as presented by professors Hersey and Blanchard. The model is aimed at equipping the manager with more diagnosing ability for the level of development or readiness of employee. Coaching style and the readiness levels are based on the situational leadership concept. In order to be more structured in leading or coaching people, the "G.R.R.O.W.S." (GRROWS) concept is introduced and abbreviation stands for the coaching process as presented in Figure 3.

- $\quad \mathbf{G}=\mathbf{G o a l}$ must be clear in leading or coaching situation

- $\quad \mathbf{R}=$ What is the reality as the coach sees it?

- $\quad \mathbf{R}=$ Wait for employee's response to the situation

- $\quad \mathbf{O}=$ What is the best option to solve the problem or pain?

- $\quad \mathbf{W}=$ What will the coachee do or action plan?

- $\quad \mathbf{S}=$ What support does the coachee need to perform the action? 
Figure 3 - Coaching Process and the "GRROWS" Elements

G.R.R.O.W.S. Model

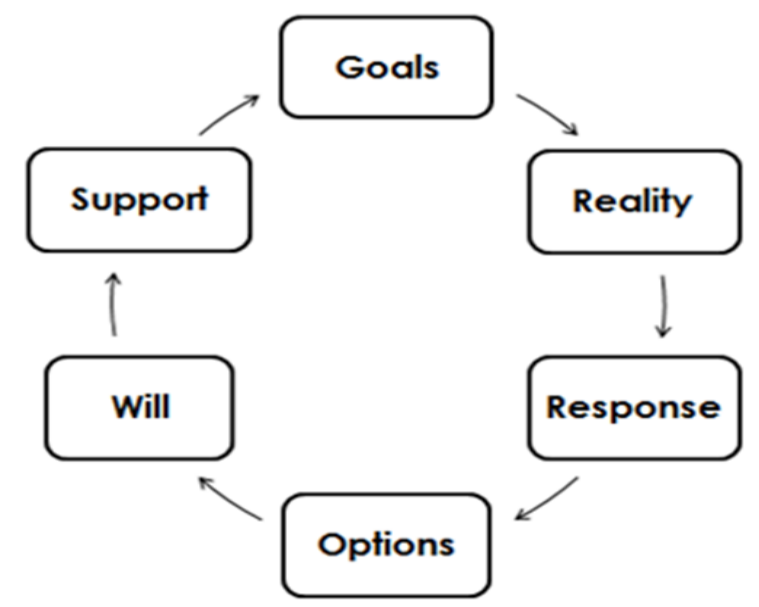

Figure 4 - Situational Coaching Model and Communication Skills

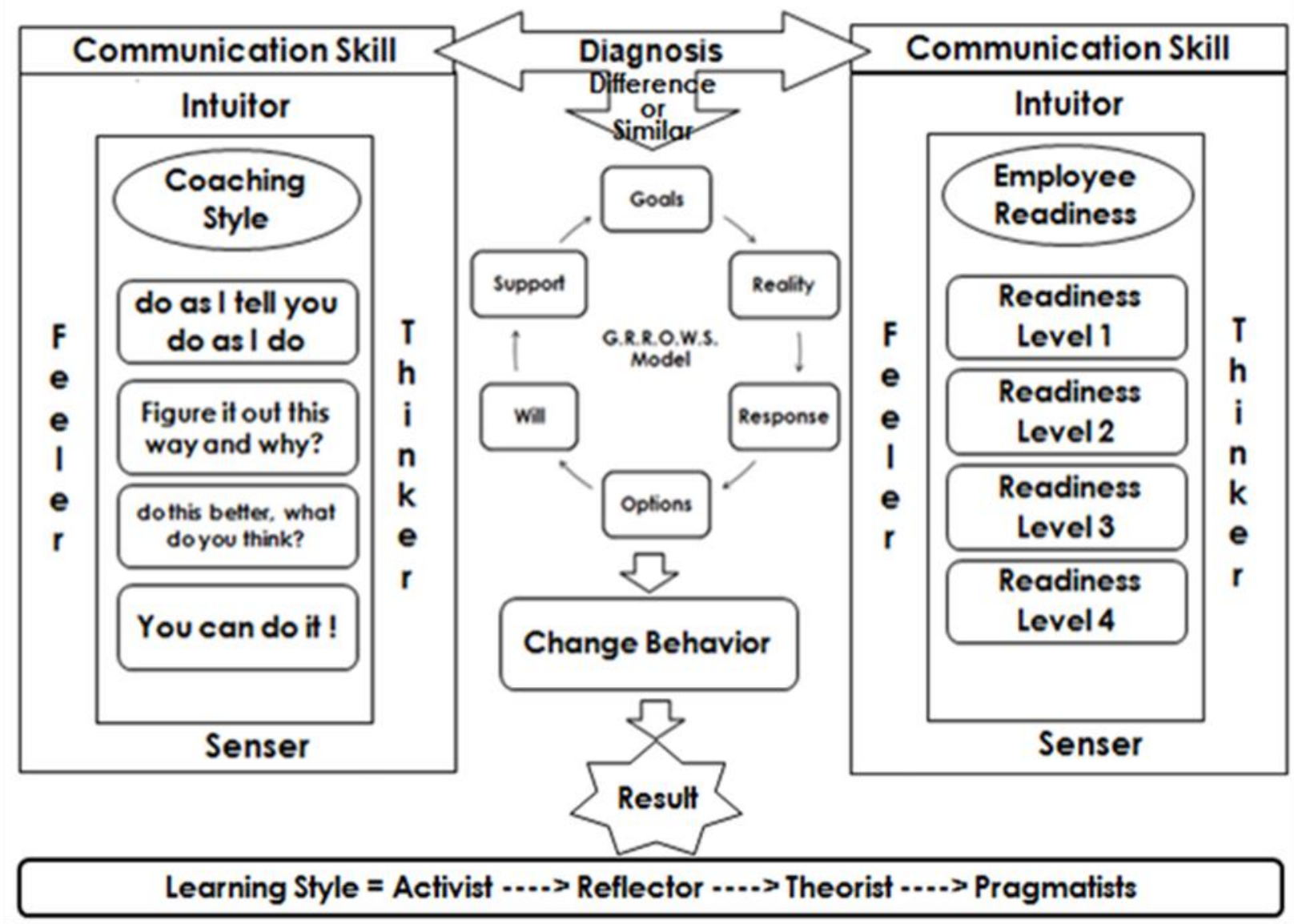


The GRROWS coaching process helps the leader follow through with employees for higher productivity and performance. In addition, the coach also needs to diagnose the communication styles of the coachees, how they prefer to communicate, i.e. with seeing big picture (intuitor), with rational (thinker), with action oriented (senser), or with caring (feeler) individuals. Coaches should also understand how the coachees best learn: do they involve themselves fully and without bias in new experiences (activist); stand back to ponder on their experiences and observe them from many different perspectives (reflectors); adapt and integrate observation into complex but logical sound theories (theorist); and keen to try out ideas, theories and techniques to see if they work in practice (pragmatist). This model helps managers to be more careful about the human aspect and to develop people incrementally with GRROWS model. Of course, managers should consider readiness or development levels and apply an appropriate coaching style and adapt to the way they prefer to be treated. The detailed, integrated, and allinclusive model is presented in Figure 4.

The last part in developing people or leading people to be more effective toward higher performance is that managers need to be supportive. Two aspects of the supportive model are the skill and knowledge support (can do) and motivation support (will do). Coaches and coachees need to jointly work on and identify the clues by asking the following questions:

- What is the obstacle?

- What are the competencies?

- What is the symptom of the obstacles?

- What are the opportunities for development?

Figure 5 - GRROWS and the Supportive Model

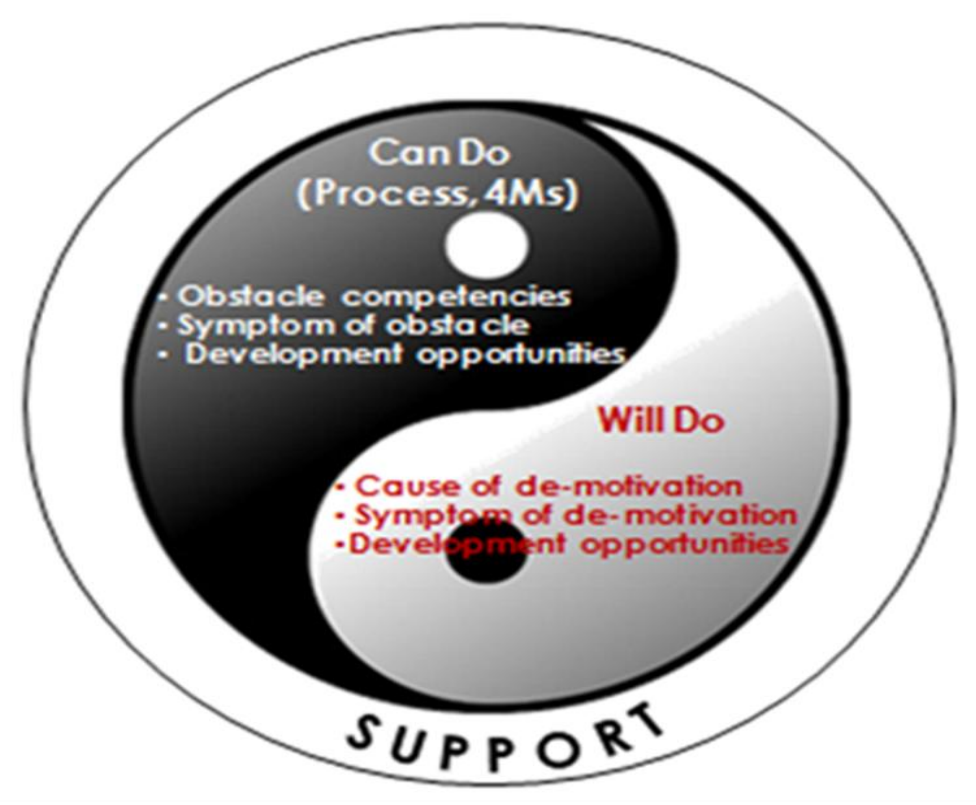

\section{SUMMARY}

Using situational leadership skills, culturally competent professionals in the workplace tend to remain focused on the readiness of their employees and colleagues and coaches them according to their level of maturity while adapting the communication style to the way others would like to be treated. In this article, the authors provided an overview of situational leadership and linked it to diversity management and coaching of individuals in 
the workplace. Furthermore, this paper provided a model to link situational leadership to diversity in the workplace through effective coaching and employee development skills.

\section{AUTHOR INFORMATION}

Bahaudin G. Mujtaba, D.B.A., is an Associate Professor of Management and Human Resources Management at Nova Southeastern University's H. Wayne Huizenga School of Business and Entrepreneurship. Bahaudin has served as manager, trainer and management development specialist in the corporate world as well as a director, department chair and faculty member in academia. His areas of research are management, training, diversity management, and cross-cultural management.

Jatuporn Sungkhawan, D.B.A., is a strategic management professional with 20 years of experience in Multinational corporations. He has been associated with some of the World's largest companies to include agribusiness, financial service and management consulting. He is a university professor who teaches Strategic Management, Business Research, and Organization Behavior. He earned the Doctorate in Business Administration degree at Nova Southeastern University's H. Wayne Huizenga School of Business and Entrepreneurship, United States. He earned a Masters of Business Administration and a Bachelors degree in Agricultural Economics at Kasetsart University, Bangkok, Thailand.

\section{REFERENCES / BIBLIOGRAPHY}

1. Cavico, F. and Mujtaba, B. G., (2008). Legal Challenges for the Global Manager and Entrepreneur. Kendal Hunt Publishing Company. United States. ISBN: 978-0-7575-4037-0.

2. Hersey, Paul (February 2008). Personal Communication on Situational Leadership. One-week Train-theTrainer Workshop by Dr. Hersey and facilitators of 'The Center for Leadership Studies.” Escondido, CA. Phone: (760) 741-6595.

3. Hersey, P.; Blanchard, K.; and Johnson, D., (2001). Management of Organizational Behavior. Eight edition. Prentice Hall. ISBN: 013-032518X.

4. Hersey, Paul (1984 \& 1997). The Situational Leader. Escondido, CA. The Center for Leadership Studies. ISBN: 0-931619-01-7. Phone: (760) 741-6595.

5. Mujtaba, B. G. (2008). Coaching and Performance Management: Developing and Inspiring Leaders. ILEAD Academy Publications; Davie, Florida, USA. ISBN: 978-0-9774211-4-5.

6. Mujtaba, B. G. (2007). Workplace Diversity Management: Challenges, Competencies and Strategies. ISBN: 1-59526-548-1. Coral Springs, Florida.

7. Mujtaba, B. G. (2007). The ethics of management and leadership in Afghanistan (2 ${ }^{\text {nd }}$ edition). ILEAD Academy. ISBN: 978-0-9774211-0-7. Davie, Florida, USA.

8. $\quad$ Pitney Bowes Inc., World Headquarters, 1 Elmcroft Road, Stamford, CT (USA).

9. Plum International Inc. (2003). A Workshop on FOCUS Coaching. Website: www.pluminternational.com. Phone: (800) 870-9490 or (954) 938-5370.

10. Pohlman, R. A. and Gardiner, G. S., (2000). Value Driven Management, How to Create and Maximize Value Over Time for Organizational Success. (NewYork) Amacom.

11. Profiles in Diversity Journal. A publication for sharing diversity information. Volume 1, number 2. Summer 1999.

12. Progressive Discipline, (2005). Legal and Effective Progressive Discipline. A 23 minute video. COASTAL Human Resources. Available through Video Training, Inc.; Phone-(800) 600-1555 or (206) 682-1555.

13. Raines, C. \& Ewing, L. (2006). The Art of connecting: How to overcome differences, build rapport, and communicate effectively with anyone. AMACOM: New York.

14. Ramsey, R., (2000). Do you need a personal coach? SuperVision, 61(7).

15. Schein, E. (1992). Organizational culture and leadership. San Francisco, CA: Jossey-Bass Company.

16. Schmitt, J, Baker, D., Bad Times: The Impact of Changes in Work Schedules on Productivity Growth, Center for Economic and Policy Research, November 2004.

17. Senge, P. (1990). The fifth discipline: The art \& practice of the learning Organization. New York: Currency Doubleday. 
18. Shellenbarger, S. How Some Innovative Employers Are Embracing Flexible Scheduling, The Wall Street Journal, November 17, 2005.

19. Siegall, M. \& McDonald, T. (2004). Person-organization value congruence, burnout and diversion of resources, Personnel Review, 33(3) 291.

20. Silverstein, B. (2007). Evaluating Performance: How to Appraise, Promote, and Fire. Harper Collins Publisher, New York, NY.

21. Silverstein, J., \& Kornacki, M. (2000). Leading physicians through change (1st ed.). Tampa, Fl: American College of Physician Executives.

22. Sketch, Edward (2001). Mentoring and Coaching Help Employees Grow. HR Focus Vol 78, no. 9, 1, 11-15.

\section{NOTES}


NOTES 